\title{
Adolescents’ Compulsive Internet Use and Depression: A Longitudinal Study
}

\author{
Einar B. Thorsteinsson, Lucy Davey \\ University of New England, Armidale, Australia \\ Email: ethorste@une.edu.au
}

Received November 23 $3^{\text {rd }}, 2013$; revised January $6^{\text {th }}$, 2014; accepted January $15^{\text {th }}, 2014$

\begin{abstract}
Copyright (c) 2014 Einar B. Thorsteinsson, Lucy Davey. This is an open access article distributed under the Creative Commons Attribution License, which permits unrestricted use, distribution, and reproduction in any medium, provided the original work is properly cited. In accordance of the Creative Commons Attribution License all Copyrights (C) 2014 are reserved for SCIRP and the owner of the intellectual property Einar B. Thorsteinsson, Lucy Davey. All Copyright (c) 2014 are guarded by law and by SCIRP as a guardian.
\end{abstract}

\begin{abstract}
Background: The present longitudinal study examined predictors of compulsive internet use and depression. Method: Adolescents, 21 males and 20 females, completed online questionnaires with a 12-month interval. Results: Social internet use (i.e., using instant messaging and social networks) was associated with decreased levels of depression. High support satisfaction, use of social networking, and instant messaging contributed to lower changes in compulsive Internet use. Conclusion: The effects of social internet use in combination with different psychosocial factors seem to have more positive effects than negative ones on change in depression and the development of compulsive internet use.
\end{abstract}

Keywords: Adolescents; Compulsive Internet Use; Coping; Social Support; Self-Esteem; Depression

\section{Introduction}

Before social media took off on the Internet in 2003/2004 (e.g., Facebook), it had been suggested that internet use was related to depression (e.g., Young \& Rodgers, 1998). Young and Rodgers reported mild to moderate depression levels being associated with internet use among males and females. Gross (2004) surveyed 12- and 15-year-old adolescents with a upper middle-class background and enrolled in a public school in the US. Gross found that most of the time adolescents spend on the internet was spent on private communication and that most of their private communication was through instant messaging. Gross reported small correlations between time online and depression and very little difference for boys and girls regarding internet use. A longitudinal study conducted in 2003 and 2004 in the Netherlands on 12- to 15-year-old adolescents found that instant messaging at Time 1 was moderately related to depression $(r=0.18)$ and compulsive internet use $(r=0.24)$ at Time 2, six months later (van den Eijnden, Meerkerk, Vermulst, Spijkerman, \& Engels, 2008). It is probably not surprising that the association between internet use and depression was not strong given that much of the internet use (e.g., instant messaging and social networking) was focused on strengthening social support networks through communications with friends and family (e.g., Subrahmanyama, Reich, Waechter, \& Espinoza, 2008). A study by Shaw and Grant (2002) of university undergraduates in the US found that internet chat sessions attenuated depression $(d=$ $0.46)$ and loneliness $(d=0.41)$ and that these chat sessions increased self-esteem $(d=0.11)$ and perceived social support ( $d \mathrm{~s}$ from 0.45 to 1.06). This study was conducted as a "reply" to a study by Kraut, Patterson, Lundmark, Kiesler, Mukopadhyay, and Scherlis (1998) that suggested that Time 2 internet use increased Time 3 depression $(r=0.15)$ and loneliness $(r=0.15)$ and reduced communication $(r=-0.08)$ and social support $(r=$ $-0.04)$.

\section{Compulsive Internet Use}

Studies conducted after 2008 in Europe and the US, after Facebook reached 100 million users, have reported mixed results for the relationship between problematic/addictive Internet use and depression among adolescents. Some studies have reported an association between Internet use and depression (e.g., Christakis, Moreno, Jelenchick, Myaing, \& Zhou, 2011; Durkee, Kaess, Floderus, Carli, \& Wasserman, 2011; Liu, Desai, Krishnan-Sarin, Cavallo, \& Potenza, 2011). However, other studies have reported that aspects of Internet use such as Facebook use (i.e., social Internet use) is not linked to depression (Jelenchick, Eickhoff, \& Moreno, 2013) despite warnings about so called “Facebook depression” (e.g., O’Keeffe \& Clarke-Pearson, 2011).

The limited and mixed findings regarding the association between social Internet use and negative mental health outcomes (e.g., depression) suggest that compulsive Internet use needs to be measured independently. A study by van den Eijnden et al. (2008) only found weak or no associations between compulsive Internet use and depression, and instant messaging and depression in adolescents. However, Meerkerk, van den Eijnden, Vermulst, and Garretsen (2007) reported compulsive Internet use in adults to be associated with negative mental health outcomes such as increased depressive symptoms $(r=0.30)$ and loneliness $(r=0.24)$ and reduced self-esteem $(r=-.31)$ and life satisfaction $(r=-.26)$.

\section{Social Support, Self-Esteem and Coping}

Psychosocial factors that are potential risk factors in the de- 
velopment of depression such as social support, self-esteem, and coping might also affect the development of compulsive Internet use in adolescents and therefore need to be examined carefully. Social support is a potentially important moderator of the effects of stressful situations on health in adults (Thorsteinsson \& James, 1999; Thorsteinsson, James, Douglas, \& Omodei, 2011; Thorsteinsson, Ryan, \& Sveinbjornsdottir, 2013) and adolescents (Burke \& Weir, 1978; Levitt, Guacci Franco, \& Levitt, 1993). Moreover, poor self-esteem is well established as one of the symptoms that specifically relates to depression in adolescents (Lewinsohn, Gotlib, \& Seeley, 1997) and can prospectively predict the likelihood of future depression in adolescents (Orth, Robins, \& Roberts, 2008).

Maladaptive coping such as rumination, acting out, and anger has been reported as a risk factor for depression in adolescents (Jose et al., 1998; Kosterman, Hawkins, Mason, Herrenkohl, Lengua, \& McCauley, 2010; Skitch \& Abela, 2008; Thorsteinsson, Ryan, et al., 2013). Maladaptive coping has also been suggested as a factor that sustains depression (Galaif, Sussman, Chou, \& Wills, 2003; Murberg \& Bru, 2005). Therefore, maladaptive coping may potentially augment and sustain depression in adolescents. Furthermore, increased rumination has been found to be associated with increased distress and reduced satisfaction with life (Thorsteinsson, Sveinbjornsdottir, Dintsi, \& Rooke, 2013), both potential pathways to increased depression.

The present study aims to increase our theoretical understanding regarding the predictors of compulsive Internet use and depression in adolescents. It will also examine the strength of the relationship between different psychological factors and social Internet use; both positive and negative relationships.

\section{Hypotheses}

The purpose of the present study was to examine the prospective effects of coping, social support, self-esteem, instant messaging and use of social networking sites on compulsive Internet use and symptoms of depression. Several hypotheses were tested: (1) there would be an association between instant messaging and social networking at Time 1 with depression at Time 2 and change in depression from Time 1 to Time 2; (2) high compulsive Internet use at Time 1 would be associated with high depression levels at Time 2 and change in depression from Time 1 to Time 2; and (3) self-esteem, coping, social support, social networking and instant messaging at Time 1 will predict change in compulsive Internet use and depression from Time 1 to Time 2 .

\section{Method}

\section{Participants}

Participants were recruited from an independent school from a small coastal town in northern New South Wales, Australia. At Time 1 there were a total of 96 participants, 52 males and 44 females, ranging from 12 to 18 years of age $(M=13.88, S D=$ 1.42 , mode $=15)$. At Time 2 there were 77 participants, 33 males and 44 females, aged from 13 to 16 years $(M=14.61, S D$ $=1.06$, mode $=15)$. Forty-one participants $(21$ males and 20 females) completed both Time 1 and Time 2 (dropout of 57\%). Their ages ranged from 12 to 15 years $(M=13.32, S D=1.15$, mode $=12$ ). Table 1 summarizes demographics for the key variables at Time 1 .

Comparison of participants that completed both Time 1 and
Table 1.

Means and standard deviations of key variables at time 1.

\begin{tabular}{cccccc}
\hline & & & \multicolumn{2}{c}{ Range } \\
\hline Measure & $n$ & $M$ & $S D$ & Possible & Actual \\
\hline Self-esteem & 41 & 2.24 & 0.76 & $1-5$ & $0.60-4.00$ \\
Social support satisfaction & 39 & 5.23 & 1.01 & $1-6$ & $1.83-6.00$ \\
Social support number & 40 & 5.68 & 2.24 & $0-9$ & $0.83-9.00$ \\
Distraction & 35 & 1.28 & 0.57 & $0-3$ & $0-2.50$ \\
Acting out & 35 & 0.54 & 0.72 & $0-3$ & $0-2.83$ \\
Rumination & 35 & 1.02 & 0.65 & $0-3$ & $0-2.67$ \\
Seeking social support & 35 & 1.12 & 0.56 & $0-3$ & $0.14-2.57$ \\
Self-care & 35 & 1.07 & 0.58 & $0-3$ & $0.14-2.86$ \\
Social networking & 32 & 2.25 & 1.53 & $1-5$ & $1.00-5.00$ \\
Instant messaging & 32 & 2.58 & 1.38 & $1-5$ & $1.00-5.00$ \\
Compulsive internet Use & 33 & 2.15 & 0.89 & $1-5$ & $1.00-4.14$ \\
Depression & 38 & 0.46 & 0.42 & $0-3$ & $0-2.14$ \\
\hline
\end{tabular}

Time $2(n=41)$ and participants that only filled in Time 1 ( $n=$ 96) revealed that the former were one year younger $(M=13.32$, $S D=1.15)$ than then latter $(M=14.23, S D=1.47)$. The Time 1 and Time 2 participants also had higher self-esteem, a larger social support network (number), and a lower depression score. The two groups had similar scores for distraction, acting out, rumination, seeking social support, self-care, social support satisfaction, instant messaging, social network, and compulsive Internet use.

\section{Measures}

The questionnaire package included demographic items regarding age and gender. Time 1 measures covered coping, social support, and self-esteem. Time 1 and Time 2 measures included compulsive Internet use, use of instant messaging and social networking, and depressive symptoms. The time interval between Time 1 and Time 2 was 12 months.

Compulsive Internet use. Compulsive Internet use was measured using the Compulsive Internet Use Scale (CIUS; Meerkerk, van den Eijnden, Vermulst, \& Garretsen, 2009). The CIUS consists of 14 statements that were adjusted in wording with Australian adolescents in mind rather than adults. Participants were asked to answer statements such as "Do you continue to use the Internet even when you intend to stop?" and "Do you think you should use the Internet less often?" on a 5point scale from 0 (Never) to 4 (Very often). For data base purposes the scale was coded from 1 to 5 , respectively. The CIUS has been found to be a reliable and valid instrument. Internal consistency has been reported and found to range from 0.82 to 0.85 (van den Eijnden et al., 2008). Internal consistency for the CIUS in the present study was 0.82 at Time 1 and 0.94 at Time 2.

Depression. Symptoms of depression were measured using the Depression sub-scale of the Depression, Anxiety, and Stress Scale (DASS-21; Lovibond \& Lovibond, 1995). The DASS-21 has good internal consistency for depression and adequate validity in a variety of populations (Antony, Bieling, Cox, Enns, \& Swinson, 1998). The scale has questions such as "I felt that life was meaningless" and is answered on a 4-point Likert scale 
ranging from 0 (Did not apply to me) to 3 (Applied to me very much, or most of the time). Internal consistency for depression was 0.78 at Time 1 and 0.93 at Time 2 .

Coping. The Measure of Adolescent Coping Strategies (Sveinbjornsdottir \& Thorsteinsson, in press) was used to assess what coping methods participants employ in stressful situations. The MACS was selected based on its psychometric properties and due to the limitations of other adolescent coping questionnaires (Sveinbjornsdottir \& Thorsteinsson, 2008). Participants were asked to think of a stressful situation that has happened to them and to then select which coping strategies they employed to cope with this situation, for example, "I talked with someone" (social support) and "I cried" (rumination). The 34-item questionnaire consists of five factors: distraction/stoicism, acting out, rumination, social support, and self-care. It is rated on a 4point scale ranging from 0 (I did not use) to 3 (I used almost all the time). The MACS has good internal consistency, ranging from 0.70 to 0.81 , and good test re-test reliability, ranging from 0.59 to 0.74 (Sveinbjornsdottir \& Thorsteinsson, in press). The MACS is based on several large data sets (e.g., 3034 and 534 Australian adolescents and 6908 Icelandic adolescents). Internal consistency for the MACS in the present study at Time 1 was 0.78 for distraction, 0.84 for acting out, 0.70 for rumination, and 0.82 for seeking social support, and 0.65 for self-care.

Social support. The Social Support Questionnaire-Short Form (SSQ-6; Sarason, Sarason, Shearin, \& Pierce, 1987) was used to measure support satisfaction and size of support network. The SSQ-6 consists of six items from the original 27item version with reliability greater than 0.90 for both versions (Sarason et al., 1987). Two scores were obtained from each item. First, participants are asked to identify persons that might provide support in the situation described (e.g., "Who can you count on to console you when you are very upset?”). Participants could select up to nine supporters for each question. Participants then rated their level of satisfaction from 1 (Very dissatisfied) to 6 (Very satisfied) with the support perceived. The SSQ-6 has high internal reliability and good convergent validity (Sarason et al., 1987). Internal consistency in the present study at Time 1 was 0.95 for social support number and 0.95 for social support satisfaction.

Self-esteem. The Rosenberg Global Self-Esteem Scale (RSES; Rosenberg, 1965) adapted by Bachman (1978) was employed to measure self-esteem. The RSES consists of ten items rated on a 5-point scale. The questions ask participants to describe what sort of a person they are by selecting how often from 1 (Never true) to 5 (Almost always true) each of the statements are true for them. Six of the items are positively worded (e.g., "I feel that I have a number of good qualities"), and four items are negatively worded (e.g., "I feel I can't do anything right”). The RSES has high internal consistency at 0.93 , good test-retest reliability (two-week interval) at 0.85 , and validity ranges from 0.56 to 0.83 (Chiu, 1988; Hagborg, 1993). Internal consistency in the present study was 0.94 at Time 1 .

Social Internet use profile. Based on the research conducted by van den Eijnden et al. (2008), participants were asked questions about how often they engaged in instant messaging and social networking. Answers were given on a 5-point scale ranging from 1 (Less than once a week) to 5 (Daily). Participants were then asked to rate how important these functions are for keeping in contact with friends from 1 (Not important at all) to 5 (Very important). These scores were then aggregated to create a mean score for instant messaging and social networking.

\section{Procedure}

Ethics approval was sought from the University of New England Human Research Ethics Committee. The questionnaire was uploaded to a secure Internet-based survey provider (surveymonkey.com) where a link to the survey was established. Participants were provided with an information statement and consent form and consent was obtained from the participant's parent or guardian prior to proceeding. Teachers then directed students to the survey link and the questionnaire was completed anonymously online under teacher supervision. Time 1 and Time 2 data were linked by matching unique identifiers across the data sets. The identifiers were created by participants at the start of Time 1 and Time 2 and were based on answers to questions that once combined, created the identifier.

\section{Statistical Analysis}

SPSS version 20 was used for general statistical analysis such as multiple regressions, correlations, and exploratory factor analysis. AMOS version 20 was used for confirmatory factor analysis of the MACS examining indices such as the Comparative Fit Index (CFI) with values above 0.90 suggesting a good fit, the Tucker-Lewis coefficient (TLI) with values close to 1 indicating a good fit, the Goodness-of-Fit index (GFI) an absolute fix index with values above 0.95 indicating a good fit, the root mean square error of approximation (RMSEA), and squared root mean residual (SRMR). RMSEA values below 0.08 and SRMR values below 0.10 are generally interpreted as favorable. An SRMR value of 0 represents a perfect fit between the model and the population covariance matrix. The confirmatory factor analysis of the MACS showed strong support for the proposed factor structure, CFI $=0.94$, TLI $=0.92$, GFI $=0.95$, RMSEA $=0.054$ [90\% CI 0.045, 0.064], and SRMR $=0.063$ (Sveinbjornsdottir \& Thorsteinsson, in press).

\section{Results}

Examining the first hypothesis, Table 2 shows that there was a strong negative association between instant messaging at Time 1 and depression at Time 2 and change in depression. High social networking at Time 1 was associated with lower increases in levels of depression (change). The second hypothesis was not supported. Compulsive Internet use at Time 1 only had a small association with depression at Time 2 and change in depression (see Table 2). The results for change in compulsive Internet use, in the third hypothesis, showed that $43 \%$ of the variance in compulsive Internet use change from Time 1 to Time 2 was explained by self-esteem, coping, social support, social networking, and instant messaging at Time 1 , adjusted $R^{2}$ $=0.43, F(7,19)=3.81, p=0.009$ (see Table 3). Examining the change in depression showed that $13 \%$ of the variance was explained by self-esteem, adaptive coping, social support, social networking, and instant messaging at Time 1, adjusted $R^{2}=$ $0.20, F(8,19)=1.83, p=0.134$ (see Table 4).

\section{Discussion}

The results show that the hypotheses were partly supported. Instant messaging and social networking use was associated with a reduction in depression over time. However, only high levels of instant messaging at Time 1 were associated with lower depression levels at Time 2 and lower change in depression 
Table 2.

Correlation matrix between key variables.

\begin{tabular}{lcccccc}
\hline & \multicolumn{3}{c}{ Depression (Time 2) } & \multicolumn{2}{c}{ Depression (Change) } \\
\hline Measure (Time 1) & $r$ & $p$ & $n$ & $r$ & $p$ & $n$ \\
\hline Instant messaging & -0.40 & 0.015 & 30 & -0.46 & 0.005 & 30 \\
Social networking & 0.13 & 0.252 & 30 & -0.28 & 0.065 & 30 \\
Compulsive internet use & -0.02 & 0.454 & 31 & -0.13 & 0.248 & 31
\end{tabular}

Note: Change $=$ Time $2-$ Time 1. $p$ values are one-tailed.

Table 3.

Regression models summary for change in compulsive internet use from time 1 to time 2 .

\begin{tabular}{lcccccc}
\hline \multicolumn{7}{c}{$95 \%$ CI for $B$} \\
\hline Predictor (Time 1) & $B$ & Lower & Upper & $\beta$ & $r$ & $s r$ \\
\hline Self-esteem & 0.18 & -0.40 & 0.75 & 0.13 & 0.34 & 0.10 \\
Distraction $^{\mathrm{a}}$ & -0.16 & -0.97 & 0.65 & -0.09 & 0.24 & -0.06 \\
Self-care $^{\mathrm{a}}$ & 0.88 & 0.16 & 1.59 & 0.48 & 0.53 & 0.38 \\
$\begin{array}{l}\text { Social support } \\
\text { satisfaction }\end{array}$ & -0.30 & -0.72 & 0.11 & -0.27 & -0.16 & -0.23 \\
$\begin{array}{l}\text { Social support } \\
\text { number }\end{array}$ & 0.03 & -0.17 & 0.23 & 0.06 & 0.34 & 0.05 \\
Social networking & -0.16 & -0.52 & 0.19 & -0.22 & -0.39 & -0.14 \\
Instant messaging & -0.21 & -0.57 & 0.15 & -0.28 & -0.57 & -0.18 \\
\hline
\end{tabular}

Note: Fit for model $R^{2}=0.58$, adjusted $R^{2}=0.43, F(7,19)=3.81, p=0.009$. The

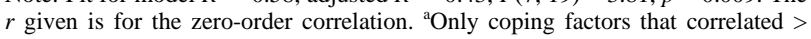
0.20 with change in compulsive Internet use were entered into the regression.

Table 4.

Regression models summary for change in depression from time 1 to time 2.

\begin{tabular}{|c|c|c|c|c|c|c|}
\hline \multicolumn{7}{|c|}{$95 \%$ CI for $B$} \\
\hline Predictor (Time 1) & $B$ & Lower & Upper & $\beta$ & $r$ & $s r$ \\
\hline Self-esteem & -0.27 & -0.90 & 0.36 & -0.23 & 0.12 & -0.16 \\
\hline Acting out ${ }^{\mathrm{a}}$ & 0.10 & -0.57 & 0.77 & 0.08 & -0.26 & 0.06 \\
\hline Rumination $^{\mathrm{a}}$ & -0.57 & -1.39 & 0.26 & -0.40 & -0.30 & -0.25 \\
\hline $\begin{array}{l}\text { Seeking social } \\
\text { support }^{\mathrm{a}}\end{array}$ & 0.29 & -0.68 & 1.26 & 0.18 & 0.17 & 0.11 \\
\hline $\begin{array}{l}\text { Social support } \\
\text { satisfaction }\end{array}$ & 0.30 & -0.13 & 0.72 & 0.34 & 0.37 & 0.25 \\
\hline $\begin{array}{l}\text { Social support } \\
\text { number }\end{array}$ & 0.00 & -0.23 & 0.23 & -0.01 & 0.13 & -0.01 \\
\hline Social networking & 0.06 & -0.31 & 0.44 & 0.11 & -0.33 & 0.06 \\
\hline Instant messaging & -0.34 & -0.74 & 0.07 & -0.50 & -0.48 & -0.30 \\
\hline
\end{tabular}

Note: Fit for model $R^{2}=0.43$, adjusted $R^{2}=0.20, F(8,19)=1.83, p=0.134$. The

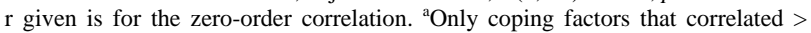
0.20 with change in depression were entered into the regression.

levels. The effects of compulsive Internet use at Time 1 on depression at Time 2 and change in depression were weak or negligible. Several factors seem to influence change in compulsive Internet use (beta $>0.20$ ). High self-care contributed to augmented compulsive Internet use levels while social support satisfaction, social networking, and instant messaging attenuated change in compulsive Internet use. These findings suggest that to protect against compulsive Internet use adolescents need to have a solid support structure, possibly sustained by social net- working and instant messaging, with low emphasis on coping by using self-care.

Four factors influenced change in depression strongly (beta > $0.20)$. These factors were high self-esteem, rumination, and use of instant messaging while depression was augmented through high support satisfaction. These findings suggest that adolescents that have a combination of high self-esteem, high instant messaging use, high rumination, and low support satisfaction are more likely to have a reduction or no change in depression levels. The association between high support satisfaction and depression may reflect the connection between seeking social support as a coping mechanism and change in depression (beta $=0.18$ ). Thus adolescents may be seeking social support to deal with changes in depression levels resulting in increased social support that in turn explains increased social support satisfaction levels.

\section{Limitations}

A small sample size increases the risk of moderate to large effect sizes not being statistically significant. However, despite a small sample size, many of the theorized effects were found to be statistically significant. The sample is limited to one independent Anglican school only further reducing any generalization from this study. However, this study does enable future studies to examine how theorized models relate to the use of instant messaging and social networking, compulsive Internet use, and depression. Future studies should consider a shorter time interval to reduce dropout. However, the time interval needs to be long enough for observable chances to occur.

\section{Conclusion}

If we only look for the negative psychological effects of social internet use on psychological and physical health using a plethora of different measures then we will find negative effects, be they meaningful or not (Shaw \& Gant, 2002). The present study suggests that the direction of effects is not self-evident when it comes to predictors of change in compulsive internet use and depression. The results indicate that mood may not be as important as previously thought in explaining adolescent behavior on the internet. Indeed, according to this study, the use of social networking and instant messaging may have beneficial effects for adolescents' mental health.

It is not new for technology to be at the forefront of discussion when it comes to adolescents. Where television, for instance, was once predicted to erode social and emotional functioning, the internet has more recently been in the spotlight. Perhaps the predicted deleterious effect of technology on psychological functioning is better explained by other factors independent of the technology. Excessive use of any technology is likely explained by pre-existing psychopathology and may be better considered a symptom of a wider problem. Importantly, we may be overlooking the potential benefits of the internet for adolescents if researchers only focus on pathology.

\section{REFERENCES}

Antony, M. M., Bieling, P. J., Cox, B. J., Enns, M. W., \& Swinson, R. P. (1998). Psychometric properties of the 42 item and 21 item versions of the depression anxiety stress scales in clinical groups and a community sample. Psychological Assessment, 10, 176-181. 


\section{E. B. THORSTEINSSON, L. DAVEY}

http://dx.doi.org/10.1037/1040-3590.10.2.176

Bachman, J. G., O’Malley, P. M., \& Johnston, J. (1978). Self-esteem and attainment: An analysis of change and stability. In J. G. Bachman, P. M. O’Malley, \& J. Johnston (Eds.), Youth in transition. Adolescence to adulthood-change and stability in the lives of young men (Vol. VI, pp. 93-120). Ann Arbor, MI: Institute for Social Research, The University of Michigan.

Burke, R. J., \& Weir, T. (1978). Benefits to adolescents of informal helping relationships with their parents and peers. Psychological Reports, 42, 1175-1184. http://dx.doi.org/10.2466/pr0.1978.42.3c.1175

Chiu, L. (1988). Testing the test: Measures of self-esteem for schoolage children. Journal of Counseling and Development, 66, 298-301. http://dx.doi.org/10.1002/j.1556-6676.1988.tb00874.x

Christakis, D. A., Moreno, M. M., Jelenchick, L., Myaing, M. T., \& Zhou, C. (2011). Problematic internet usage in US college students: A pilot study. BMC Medicine, 9, 77. http://dx.doi.org/10.1186/1741-7015-9-77

Durkee, T., Kaess, M., Floderus, B., Carli, V., \& Wasserman, D. (2011). FC09-06-Adolescent Internet behaviors and its correlation to depression, self-harm and suicidal behavior. European Psychiatry, 26, 1863. http://dx.doi.org/10.1016/S0924-9338(11)73567-2

Galaif, E. R., Sussman, S., Chou, C. P., \& Wills, T. A. (2003). Longitudinal relations among depression, stress, and coping in high risk youth. Journal of Youth and Adolescence, 32, 243-258.

http://dx.doi.org/10.1023/A:1023028809718

Gross, E. F. (2004). Adolescent internet use: What we expect, what teens report. Journal of Applied Developmental Psychology, 25, 633649. http://dx.doi.org/10.1016/j.appdev.2004.09.005

Hagborg, W. J. (1993). The Rosenberg self-esteem scale and Harter's self-perception for adolescents: A concurrent validity study. Psychology in the Schools, 30, 132-136.

http://dx.doi.org/10.1002/1520-6807(199304)30:2<132::AID-PITS23 10300205>3.0.CO;2-Z

Jelenchick, L. A., Eickhoff, J. C., \& Moreno, M. A. (2013). "Facebook depression?” Social networking site use and depression in older adolescents. Journal of Adolescent Health, 52, 128-130.

http://dx.doi.org/10.1016/j.jadohealth.2012.05.008

Jose, P. E., D’Anna, C. A., Cafasso, L. L., Bryant, F. B., Chiker, V., Gein, N., \& Zhezmer, N. (1998). Stress and coping among Russian and American early adolescents. Developmental Psychology, 34, 757769. http://dx.doi.org/10.1037/0012-1649.34.4.757

Kosterman, R., Hawkins, J. D., Mason, W. A., Herrenkohl, T. I., Lengua, L. J., \& McCauley, E. (2010). Assessment of behavior problems in childhood and adolescence as predictors of early adult depression. Journal of Psychopathology and Behavioral Assessment, 32, 118127. http://dx.doi.org/10.1007/s10862-009-9138-0

Kraut, R., Patterson, M., Lundmark, V., Kiesler, S., Mukopadhyay, T., \& Scherlis, W. (1998). Internet paradox: A social technology that reduces social involvement and psychological well-being? American Psychologist, 53, 1017-1031. http://dx.doi.org/10.1037/0003-066X.53.9.1017

Levitt, M. J., Guacci Franco, N., \& Levitt, J. L. (1993). Convoys of social support in childhood and early adolescence: Structure and function. Developmental Psychology, 29, 811-818.

http://dx.doi.org/10.1037/0012-1649.29.5.811

Lewinsohn, P. M., Gotlib, I. H., \& Seeley, J. R. (1997). Depression-related psychosocial variables: Are they specific to depression in adolescents? Journal of Abnormal Psychology, 106, 365-375. http://dx.doi.org/10.1037/0021-843X.106.3.365

Liu, T. C., Desai, R. A., Krishnan-Sarin, S., Cavallo, D. A., \& Potenza, M. N. (2011). Problematic Internet use and health in adolescents: Data from a high school survey in Connecticut. Childhood and Adolescent Mental Health, 72, 836-845.

Lovibond, P. F., \& Lovibond, S. H. (1995). The structure of negative emotional states: Comparison of the Depression Anxiety Stress Scales (DASS) with the Beck Depression and Anxiety Inventories. Behaviour Research and Therapy, 33, 335-343. http://dx.doi.org/10.1016/0005-7967(94)00075-U

Meerkerk, G.-J., van den Eijnden, R. J. J. M., Vermulst, A. A., \& Garretsen, H. F. L. (2007). The relationship between personality, psychosocial wellbeing and compulsive internet use: The internet as cy- ber Prozac? In G.-J. Meerkerk (Ed.), Pwned by the internet: Explorative research into the causes and consequences of compulsive internet use (pp. 86-99). Rotterdam: IVO.

Meerkerk, G.-J., van den Eijnden, R. J. J. M., Vermulst, A. A., \& Garretsen, H. F. L. (2009). The Compulsive Internet Use Scale (CIUS): Some psychometric properties. Cyber Psychology \& Behavior, 12, 16. http://dx.doi.org/10.1089/cpb.2008.0181

Murberg, T. A., \& Bru, E. (2005). The role of coping styles as predictors of depressive symptoms among adolescents: A prospective study. Scandinavian Journal of Psychology, 46, 385-393.

http://dx.doi.org/10.1111/j.1467-9450.2005.00469.x

O’Keeffe, G. S., \& Clarke-Pearson, K. (2011). The impact of social media on children, adolescents, and families. Pediatrics, 127, 800804. http://dx.doi.org/10.1542/peds.2011-0054

Orth, U., Robins, R. W., \& Roberts, B. W. (2008). Low self-esteem prospectively predicts depression in adolescence and young adulthood. Journal of Personality and Social Psychology, 95, 695-708. http://dx.doi.org/10.1037/0022-3514.95.3.695

Rosenberg, M. (1965). Society and the adolescent self-image. Princeton, NJ: Princeton University Press.

Sarason, I. G., Sarason, B. R., Shearin, E. N., \& Pierce, G. R. (1987). A brief measure of social support: Practical and theoretical implications. Journal of Social and Personal Relationships, 4, 497-510. http://dx.doi.org/10.1177/0265407587044007

Shaw, L. H., \& Gant, L. M. (2002). In defense of the internet: The relationship between Internet communication and depression, loneliness, self-esteem, and perceived social support. Cyber Psychology \& Behavior, 5, 157-171. http://dx.doi.org/10.1089/109493102753770552

Skitch, S. A., \& Abela, J. R. Z. (2008). Rumination in response to stress as a common vulnerability factor to depression and substance misuse in adolescence. Journal of Abnormal Child Psychology, 36, 10291045. http://dx.doi.org/10.1007/s10802-008-9233-9

Subrahmanyama, K., Reich, S. M., Waechter, N., \& Espinoza, G. (2008). Online and offline social networks: Use of social networking sites by emerging adults. Journal of Applied Developmental Psychology, 29, 420-433. http://dx.doi.org/10.1016/j.appdev.2008.07.003

Sveinbjornsdottir, S., \& Thorsteinsson, E. B. (2008). Adolescent coping scales: A critical psychometric review. Scandinavian Journal of Psychology, 49, 533-548. http://dx.doi.org/10.1111/j.1467-9450.2008.00669.x

Sveinbjornsdottir, S., \& Thorsteinsson, E. B. (in press). Psychometric properties of the Measure of Adolescent Coping Strategies (MACS). Psychology.

Thorsteinsson, E. B., \& James, J. E. (1999). A meta-analysis of the effects of experimental manipulations of social support during laboratory stress. Psychology \& Health, 14, 869-886. http://dx.doi.org/10.1080/08870449908407353

Thorsteinsson, E. B., James, J. E., Douglas, M. E., \& Omodei, M. M. (2011). Effects of social support on cardiovascular and cortisol reactivity during passive and active behavioural challenge. Journal of Psychiatry, Psychology and Mental Health, 3, 1-12.

Thorsteinsson, E. B., Ryan, S., \& Sveinbjornsdottir, S. (2013). The mediating effects of social support and coping on the stress-depression relationship in rural and urban adolescents. Open Journal of Depression, 2, 1-6. http://dx.doi.org/10.4236/ojd.2013.21001

Thorsteinsson, E. B., Sveinbjornsdottir, S., Dintsi, M., \& Rooke, S. E. (2013). Negative life events, distress, and coping among adolescents in Botswana. Australian Journal of Educational \& Developmental Psychology, 13, 75-86.

van den Eijnden, R. J. J. M., Meerkerk, G.-J., Vermulst, A. A., Spijkerman, R., \& Engels, R. C. M. E. (2008). Online communication, compulsive Internet use, and psychosocial well-being among adolescents: A longitudinal study. Developmental Psychology, 44, 655-665. http://dx.doi.org/10.1037/0012-1649.44.3.655

Young, K. S., \& Rodgers, R. C. (1998). The relationship between depression and Internet addiction. Cyber Psychology \& Behavior, 1, 2528. http://dx.doi.org/10.1089/cpb.1998.1.25 